\title{
Consequences of genetic erosion on fitness and phenotypic plasticity in European tree frog populations (Hyla arborea)
}

\author{
E. LUQUET*, J.-P. LÉNA*, P. DAVID†, P. JOLY*, T. LENGAGNE*, N. PERRIN† \& S. PLÉNET* \\ *Université Lyon1, CNRS UMR 5023 Ecologie des Hydrosystèmes Fluviaux, Université Claude Bernard Lyon1, Université de Lyon, Villeurbanne Cedex, France \\ †Centre d'Ecologie Fonctionnelle et Evolutive UMR 5175, Montpellier, France \\ \$Département d’Ecologie et Evolution, Université de Lausanne, Lausanne, Suisse
}

\section{Keywords:}

inducible defence;

habitat fragmentation;

costs;

environmental stress;

inbreeding;

heterosis.

\begin{abstract}
The detrimental effects of genetic erosion on small isolated populations are widely recognized contrary to their interactions with environmental changes. The ability of genotypes to plastically respond to variability is probably essential for the persistence of these populations. Genetic erosion impact may be exacerbated if inbreeding affects plastic responses or if their maintenance were at higher phenotypic costs. To understand the interplay 'genetic erosionfitness-phenotypic plasticity', we experimentally compared, in different environments, the larval performances and plastic responses to predation of European tree frogs (Hyla arborea) from isolated and connected populations. Tadpoles from isolated populations were less performant, but the traits affected were environmental dependant. Heterosis observed in crosses between isolated populations allowed attributing their low fitness to inbreeding. Phenotypic plasticity can be maintained in the face of genetic erosion as inducible defences in response to predator were identical in all populations. However, the higher survival and developmental costs for isolated populations in harsh conditions may lead to an additional fitness loss for isolated populations.
\end{abstract}

\section{Introduction}

Populations characterized by reduced size or isolation resulting from habitat loss and fragmentation generally exhibit a reduced genetic diversity caused by restricted gene flow, genetic drift and inbreeding (Hedrick, 2001; Reed, 2005; Willi et al., 2006). As a consequence, genetic erosion is assumed to decrease the mean fitness of populations (Reed \& Frankham, 2003). Numerous studies have observed such a relationship (e.g. Bijlsma et al., 2000; Hooftman et al., 2003; Rowe \& Beebee, 2003; Reed \& Bryant, 2004; Reed, 2005; Willi et al., 2007b). In these studies, mean fitness was generally assessed through mean survival, fecundity and growth rate in standard

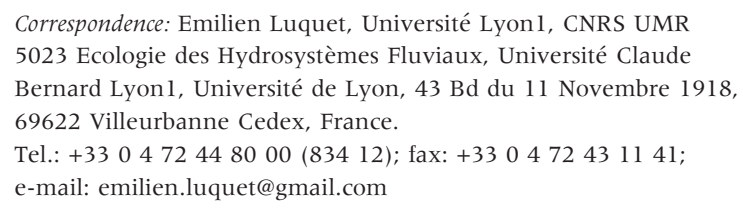

conditions. Adaptive phenotypic plasticity, i.e. favoured by natural selection, has however rarely been considered.

Yet phenotypic plasticity may be of great importance in small isolated populations in which the evolutionary response is expected to be limited by a lowered additive genetic variance (Pertoldi et al., 2007). In such a situation, the persistence of isolated populations may be based on the capacity of few genotypes to react to environmental changes in a plastic way (Sultan, 2000; Pigliucci, 2005; Pertoldi et al., 2007; Schlichting, 2008). However, the effects of genetic erosion may interact with phenotypic plasticity patterns. A recent meta-analysis does not show ample evidence that plasticity is a costly trait in itself, i.e. that individuals pay a large price to carry the option to be plastic (plasticity costs; Van Buskirk $\delta$ Steiner, 2009); therefore, there is no particular reason to expect that inbreeding and genetic erosion would decrease rather than increase plasticity in general. Yet plastic responses often involves a complex and costly shift (production costs defined by DeWitt et al., 1998; 
Auld et al., 2010; phenotypic costs defined by Callahan et al., 2008) in the developmental trajectory that increases fitness in specific environmental conditions. As any fitness trait, such plasticity can be affected by deleterious mutations whose effect is amplified by inbreeding. The deleterious effects of inbreeding on the expression of phenotypes may be more visible under conditions that reveal more inter-individual variation. In addition, induced phenotypes may become more costly to produce because of the poor general condition of individuals caused by inbreeding. This is suggested by the observation that costs associated with expression of phenotypes seems to be greater or more easily detected under stressful conditions, i.e. when individual condition is lowered for environmental, rather than genetic reasons (Huber et al., 2004; Teplitsky et al., 2005a). Consequently, genetic erosion may impact the expression and the associated costs of plastic responses.

However, such a relationship between plasticity and genetic erosion has not yet been clearly confirmed. Indeed, whereas some studies suggest a reduction in plasticity in genetically eroded populations of plants and animals (Paschke et al., 2003; Pluess \& Stocklin, 2004; Auld \& Relyea, 2010), Berg et al. (2005) did not observe any alteration of plastic response within small isolated populations of plant relative to connected ones. To our knowledge, no study has investigated the costs of inducible phenotypes in relation to the genetic variability of populations.

Anuran amphibians are useful models for the study of genetic erosion and its consequences on fitness and on phenotypic plasticity. Small isolated populations in many species are increasingly common mainly because of habitat fragmentation (Lesbarreres et al., 2003; Cushman, 2006; Gallant et al., 2007). Furthermore, larvae of many species of anurans have been shown to exhibit phenotypic plasticity expressed through different developmental components, adaptive morphology and behaviour (e.g. Van Buskirk, 2002; Laurila et al., 2002; Merila et al., 2004; Relyea, 2004). Inducible defences are adaptive plastic responses increasing survival that result from spatial and temporal variability in predation risk. Their expressions provide a higher survival but are associated with phenotypic costs (reduction in growth and developmental rates), depending on the degree and the temporal variability of predation risk (e.g. Van Buskirk, 2000; Van Buskirk et al., 2002; Teplitsky et al., 2005a,b; Capellan \& Nicieza, 2007; Teplitsky \& Laurila, 2007).

Here, we proposed to assess in small isolated populations of European tree frogs (Hyla arborea) the impact of genetic erosion on (i) the mean fitness of populations, (ii) the expression of inducible defences and (iii) the phenotypic costs of inducible defences. We experimentally compared the performances of $H$. arborea tadpoles and the expression of inducible defences in small isolated populations relative to large connected ones. We additionally used interpopulational crosses to test whether performances may be restored when inbreeding was suppressed (i.e. to test for a heterotic effect upon outbreeding). We expected tadpoles from isolated populations to show reduced performances and heterosis upon outbreeding. To broaden the range of conditions under which we could detect the effects of genetic erosion on fitness and on inducible defences, we reared tadpoles in two contrasted environments: one was unfavourable because of harsh conditions (in our case, low oxygen concentrations and restricted diet) and the other one was favourable because of benign conditions (i.e. normoxia and ad libitum diet). Environmental stress has often been suspected to enhance deleterious effects of inbreeding although the evidence remains mixed (Keller \& Waller, 2002; Armbruster \& Reed, 2005; Szulkin \& Sheldon, 2007; Willi et al., 2007a; Waller et al., 2008).

\section{Material and methods}

The European tree frog ( $H$. arborea) was chosen for this study because some populations in Europe suffer from genetic erosion as a result of habitat fragmentation (Andersen et al., 2004; Broquet et al., 2010) and are disappearing in several regions of Europe (Fog, 1993). Moreover, tadpoles of this species exhibit a well-known phenotypic plasticity strategy in response to predation risk (i.e. increase in tail fin depth relative to body size; Lardner, 2000; Van Buskirk, 2000, 2002; Teplitsky et al., 2003).

\section{Study area and source populations}

We used $H$. arborea populations located in two areas in the same region (i.e. Isère department, South-Eastern France). We surveyed these populations during two consecutive years (Broquet et al., 2010). The first area is the Gresivaudan valley (40 km from Grenoble) and is characterized by high industrialization since the 1960s that has led to landscape fragmentation and isolation of amphibian populations. As a consequence, the two populations sampled in two isolated sites (Cheylas C and Laissaud L geographically distant by $10 \mathrm{~km}$, $45^{\circ} 23^{\prime} 46^{\prime \prime} \mathrm{N}$, $5^{\circ} 59^{\prime} 41^{\prime \prime} \mathrm{E}$ and $45^{\circ} 28^{\prime} 18.02^{\prime \prime} \mathrm{N}, 6^{\circ} 3^{\prime} 51.02^{\prime \prime} \mathrm{E}$, respectively) are small (females $=30-50$ and 15-25, respectively) and genetically impacted. Broquet et al. (2010) analysed these populations with 18 microsatellite loci. They demonstrated the negative consequences of disconnection on allelic richness and gene diversity and that the decrease in population effective size in association to disconnection acts as a genetic bottleneck. The second area (the Isle Cremieu, $40 \mathrm{~km}$ from Lyon, $70 \mathrm{~km}$ from the first area) is a large plateau $\left(15 \mathrm{~km}^{2}\right)$ where over two hundred ponds and marshes constitute potential amphibian breeding sites. In the two sampled sites (Planches $\mathrm{P}$ and Mépieu $\mathrm{M}$ geographically distant by $8 \mathrm{~km}, 45^{\circ} 44^{\prime} 20^{\prime \prime} \mathrm{N}, 5^{\circ} 21^{\prime} 7^{\prime \prime} \mathrm{E}$ and $45^{\circ} 44^{\prime} 3^{\prime \prime} \mathrm{N}, 5^{\circ} 27^{\prime} 21^{\prime \prime} \mathrm{E}$ respectively), tree frog populations are large $(>200$ 
females) and genetically variable relative to the isolated populations (Broquet et al., 2010). In this study, we have contrasted the two small isolated populations against the two large connected ones without separating the effects of population size from those of isolation. Although this question deserves attention, our focus was more on the effects of genetic erosion, which is a common consequence of both small population size and isolation. Moreover, in a conservation perspective, fragmentation of habitats often results in simultaneous decreases in population size and connectivity.

Both isolated and connected areas presented similar elevation (between 250 and $350 \mathrm{~m}$ ) and climatic conditions during 2007 and 2008 (mean $T_{\min }=6.1$ and $8.3^{\circ} \mathrm{C}$, mean $T_{\max }=16$ and $16.5^{\circ} \mathrm{C}$, mean precipitations $=74$ and $72.3 \mathrm{~mm}$, respectively, for isolated and connected areas; http://www.meteofrance.com). Ponds are all permanent, range in surface area from 25 to $80 \mathrm{~m}^{2}$, with a bottom in gentle slopes and globally the same maximum depth $(<1.5 \mathrm{~m})$. They are well vegetated and located in terrestrial habitat with a large forest cover. The terrestrial vegetation cover is however slightly more important in the area of connected populations. In terms of predation risk, all four of the sampled ponds had a high density of predatory insects for tadpoles (Odonata larvae) during the study period (Luquet et al., personal observations).

\section{Laboratory experiments}

We compared the performances and the ability to express defences of $H$. arborea tadpoles according to their population status (isolated or connected) and the predation risk (with or without predator) in two contrasted environments (harsh and benign conditions). Because of the difficulty of sampling enough individuals in the small isolated populations, we had to conduct the experiments in harsh and benign conditions over two different years. We are well aware that this is problematic, but such problems are inherent to the study of small populations. However, both years were climatically similar (mean $T_{\min }=7.3$ and $7.2{ }^{\circ} \mathrm{C}$, mean $T_{\max }=15$ and $16.1^{\circ} \mathrm{C}$, mean precipitation $=69.3$ and $77 \mathrm{~mm}$, respectively, in 2007 and 2008; Météo-France data), and tadpoles were collected at similar times of the breeding cycle (from 15th April).

In 2007, we were also not able to obtain enough successful matings in the second pair of populations (L and $\mathrm{M}$ populations). We then reared only tadpoles from the $\mathrm{C}$ isolated and the $\mathrm{P}$ connected populations in harsh conditions to exacerbate the effect of genetic erosion on tadpole performances (Table 1).

In 2008, we reared tadpoles from both isolated ( $\mathrm{C}$ and $\mathrm{L})$ and both connected ( $\mathrm{M}$ and $\mathrm{P}$ ) populations in benign conditions (Table 1). We also set up experimental crosses between populations from the same status (noted interpopulational crosses; Table 1). If inbreeding is responsible for fitness losses in small populations, fitness should increase under outbreeding. Because of the very small number of females (15-25) in the L population, we were not able to perform reciprocal crosses (i.e. L females $\times \mathrm{C}$ males). To follow the same design in connected populations, we also performed asymmetrical interpopulational crosses (only $\mathrm{M}$ females $\times \mathrm{P}$ males; Table 1 ).

During each year and from 15 April, males and females were caught at night, and random pairs were quickly formed in transparent tanks $(17.5 \times 33 \times 18.5 \mathrm{~cm})$ filled with pond water and vegetation to simulate a natural breeding zone. In each area, breeding tanks were placed close to one pond, and all crosses were performed at the same place (Table 1). When necessary, the animals were quickly transported by car after capture and placed in the tanks. We used each animal only once for reproduction.

Table 1 Description of the experimental design for each year. In 2008, we could not rear within a tank one tadpole from all clutches because each of the 16 partitioned tanks could only receive 48 tadpoles. Therefore, we randomly distributed in a first set of eight tanks, one tadpole from six clutches per population and interpopulational cross. The other sampled tadpoles (from the six others clutches per population and interpopulational cross) were introduced in a second set of eight tanks. In the L population, we used two tadpoles per clutch because only six clutches had been obtained.

\begin{tabular}{|c|c|c|}
\hline Year & 2007 & 2008 \\
\hline Isolated population & C & $\mathrm{C}$ and $\mathrm{L}$ \\
\hline Connected population & $\mathrm{P}$ & $\mathrm{P}$ and $\mathrm{M}$ \\
\hline \multirow[t]{2}{*}{ Intrapop. cross (site of pair realization) } & $\mathrm{C} \times \mathrm{C}(\mathrm{C}$ site $)$ & $C \times C ; L \times L(C$ site $)$ \\
\hline & $\mathrm{P} \times \mathrm{P}(\mathrm{P}$ site $)$ & $P \times P ; M \times M(P$ site $)$ \\
\hline \multirow[t]{2}{*}{ Interpop. cross (site of pair realization) } & / & $\mathrm{C}$ female $\times \mathrm{L}$ male $(\mathrm{C}$ site $)$ \\
\hline & & $\mathrm{M}$ female $\times \mathrm{P}$ male $(\mathrm{P}$ site $)$ \\
\hline No. clutches per cross & $12($ total = 24) & 12 (except $L \times L n=6$ ) (total $=66$ ) \\
\hline No. tadpoles per clutch & 16 (total = 384) & 8 (except $L \times L n=16)($ total $=576)$ \\
\hline \multirow[t]{3}{*}{ Tanks $=$ replicates } & 4 tanks without aeshna & 8 ( $4 \times 2$ set) tanks without aeshna \\
\hline & 4 tanks with 6 aeshna & 8 ( $4 \times 2$ set $)$ tanks with 6 aeshna \\
\hline & ( 2 tadpoles per clutch per tank) & ( 1 tadpole per clutch per tank) \\
\hline Rearing conditions & Harsh (hypoxia, restricted diet) & Benign (normoxia, ad libitum diet) \\
\hline Day of measure & 31 & 23 \\
\hline
\end{tabular}




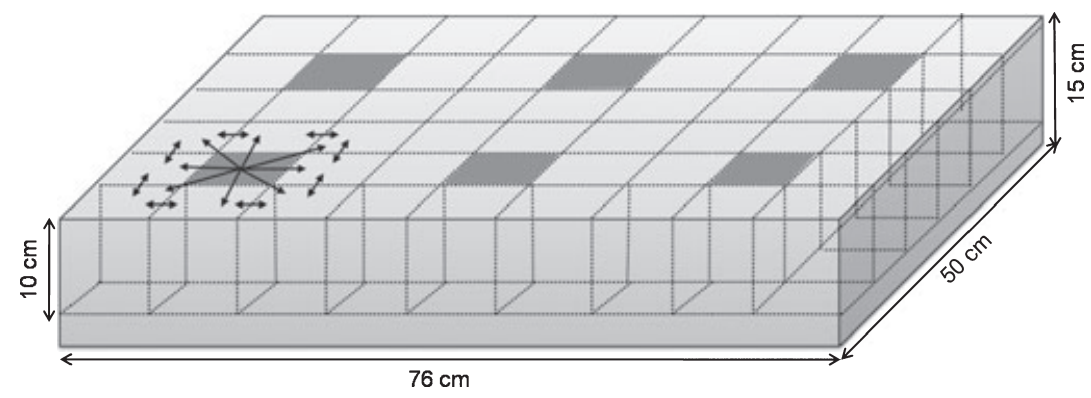

Fig. 1 Partitioned tanks used for individual rearing of tadpoles. The tanks were closed. All the compartments were permeable (wire netting of plastic), allowing free movement of water within the tank and a homogeneous diffusion of predator cues. Depending on the treatment, aeshna were (or were not) kept in the shaded compartments; $\mathrm{O}_{2}$ diffusers were present in the same compartments only in the benign conditions.

Clutches were obtained within the first $24 \mathrm{~h}$. After hatching, tadpoles from 12 pairs per type of cross were transported to the laboratory (Table 1). When tadpoles were 7 days old (stage 24-25, free-swimming stage, Gosner, 1960), they were individually reared in 55-L transparent plastic tanks with 54 permeable compartments $(6 \times 9$ compartments per tank; Fig. 1). Six compartments were empty or contained one predator depending on the treatment. All the compartments were permeable (plastic wire netting), allowing free movement of water within the tank. Before the experiments, we added a drop of dye in each shaded compartment; this confirmed that water diffusion was rapid and relatively homogeneous in all the compartments. Thus, we assume a rapid and homogeneous diffusion of predator cues in the tank during the experiments. Given the position of predators within the tanks, all tadpoles were similarly exposed to predator cues (Fig. 1). We used dragonfly larvae (Aeshna sp.) as predators. The experimental treatment with six predators was approximately similar to the ponds with highest Aeshnidae densities in nature $\left(14 \mathrm{~m}^{-2}\right.$; Van Buskirk et al., 2003). Aeshna larvae were fed with $H$. arborea tadpoles every 2 days as it is known that kaïromone (chemical cue released by predators and hunted tadpoles) induces a full defensive response in tadpoles (Van Buskirk \& Arioli, 2002). The tanks were randomly distributed in an experimental room that was maintained at $22.5^{\circ} \mathrm{C}\left( \pm 0.8{ }^{\circ} \mathrm{C}\right)$ and with a $12: 12 \mathrm{~h}$ light-dark cycle. Water in the tanks was renewed every 10 days until the measures of tadpole performances were performed (i.e. at 31 and 23 days in harsh and benign conditions), then three and two times, in harsh and benign conditions, respectively.

\section{Harsh condition experiment}

To create harsh conditions, we restricted the tadpole diet with 1 day of starvation every 2 days. The second day, tadpoles were fed with spinach and boiled lettuce ad libitum. Moreover, the tanks were covered to limit oxygen exchanges with the atmosphere, and the water was not oxygenated. Consequently, mean water oxygen concentration, checked every day (WTW Oxi 320 oxymeter, WTW, Weilheim, Germany), was low during the entire experiment (mean $\mathrm{O}_{2}$ concentration $=3.3 \pm$ $0.7 \mathrm{mg} \mathrm{O}_{2} \mathrm{~L}^{-1}$ ). Although this value can be within the range of oxygen concentrations recorded over nycthemeral cycles in natural ponds, a continuous value across the day and during the entire larval period is rarely observed and is necessarily stressful. This value seems to constitute a good compromise between stressful conditions and the survival of $H$. arborea tadpoles (Luquet et al., personal observations).

On 25 May 2007, we randomly sampled 16 tadpoles in each of the 24 clutches (Table 1 ). We randomly distributed two tadpoles per clutch in each of the eight partitioned tanks. Four tanks were without and four tanks with predators (Table 1).

\section{Benign condition experiment}

In the benign conditions, the tadpoles were fed daily ad libitum with spinach and boiled lettuce. The tanks were also covered but with six $\mathrm{O}_{2}$ diffusers in each tank (Fig. 1), mean water oxygen concentration was normoxic during the entire experiment (mean $\mathrm{O}_{2}$ concentration $=7.4 \pm 0.4 \mathrm{mg} \mathrm{O}_{2} \mathrm{~L}^{-1}$ ).

On 20 May 2008, we randomly sampled eight tadpoles in each of the 60 clutches from C, P and M intrapopulational crosses and from both interpopulational crosses (Table 1). As in the L isolated population, we were able to obtain only six clutches, we sampled 16 tadpoles per clutch. We could not rear one tadpole from all clutches because each of the 16 partitioned tanks could only receive 48 tadpoles (Fig. 1). We then randomly distributed in a first set of eight tanks one tadpole from six clutches per intra- and interpopulational cross. The other sampled tadpoles (from the six others clutches per intra- and interpopulational cross) were introduced into a second set of eight tanks. In the L population, we used two tadpoles per clutch. Eight tanks (four per set) were without Aeshna and eight others (four per set) with predators (Table 1).

\section{Plasticity and larval performance measures}

Aeshnidae predators are known to cause principally an adaptive change in tail fin depth in many larval anuran 
species (e.g. Van Buskirk \& McCollum, 2000; Van Buskirk et al., 2003; Teplitsky et al., 2004, 2005b). In this respect, $H$. arborea is the most sensitive species (see Van Buskirk, 2002). Moreover, on the first year (harsh conditions experiment), we measured five morphological traits known to exhibit predator-induced plasticity: tail length, tail fin depth, tail muscle depth, body length and body depth. Tail fin depth was the trait the most modified by the presence of Aeshna. Consequently, we have only presented the results referring to this trait (see results for other traits in Table S5 and Fig. S1) and only investigated this trait in the second experiment (benign conditions). The maximum tail fin depth was measured (to the nearest $0.1 \mathrm{~mm}$ ) using a stereoscopic microscope equipped with an ocular micrometre to assess tadpole investment in inducible defences. As morphological changes in response to predation are usually measured within 20-40 days and approximately at Gosner stage 30-37 (Van Buskirk, 2002), we performed tadpoles measures at 31 and 23 days in harsh and benign conditions, respectively, stages that correspond approximately to the mid-development for $H$. arborea. We also estimated the proportion of surviving tadpoles and measured the growth and developmental performances of all tadpoles (wet body mass to the nearest $0.1 \mathrm{mg}$ and total length to the nearest $0.1 \mathrm{~mm}$; stage according to Gosner, 1960). Results for total length are not presented because of their high redundancy with body mass.

\section{Statistical analyses}

The tadpole performances were analysed using mixedeffects models (Pinheiro \& Bates, 2000). We performed both analyses of covariances (ANCOVAS) and analyses of variances (ANovAs) with type III mean squares, using expected means squares method. This method tested significance of effects in a conservative way.

Inducible defences were analysed with tail fin depth as the dependent variable and body mass as the control variable. Tail fin depth and covariate body mass were log transformed to linearize the relationship (Teplitsky $\delta$ Laurila, 2007).

Larval performances of tadpoles (survival, developmental stage and body mass measured on 31 days in harsh and 23 days in benign conditions) were first analysed with Anovas. Because all tadpoles survived in benign conditions, we did not perform an analysis on this survival measure. Secondly, to compare the relative investment within body mass relative to the developmental stage of tadpoles, we introduced body mass as the dependent variable and stage as the control variable.

The results of the two experiments were analysed separately because they were not performed the same year. The tadpole performances in the harsh conditions (except survival) were analysed with predation treatment as the main fixed effect; tank within predation treatment, population and the interaction with predation treatment were random effects. Tadpole survival was analysed with a generalized linear model using the logit link and a binomial error distribution. This model included however only fixed effects. In the benign conditions experiment, we performed two analyses. First, the differences in the performances of tadpoles from intrapopulational crosses were analysed in the same way as in harsh conditions (analysis detailed earlier). Secondly, to test whether differences in performances following population status are because of inbreeding, we compared the performances of tadpoles from intra$(\mathrm{C}$ and $\mathrm{M}$ ) and interpopulational ( $\mathrm{C}$ female $\times \mathrm{L}$ male and $\mathrm{M}$ female $\times \mathrm{P}$ male) crosses. Predation treatment, male population (same or different from the female) and the interaction between these factors were the main fixed effect; tank within predation treatment, female populations, interaction between female, male populations and predation treatment were random effects.

In all the analyses, the nonsignificant interactions were eliminated from the model to obtain the final model. For all the analyses, conditions of variance homogeneity were checked. JMP 8.0 (SAS Institute, Cary, NC, USA) was used for all the statistical analyses.

\section{Results}

\section{Effect of genetic erosion on mean population fitness}

In benign conditions, tadpoles from crosses within isolated populations ( $\mathrm{C}$ and L) showed lower performances than those from connected populations ( $M$ and P) whatever the predation treatment (Fig. 2, Table 2A). The tadpoles from isolated populations were always less developed and lighter than tadpoles from connected populations in $\mathrm{C}<\mathrm{L}<\mathrm{P}<\mathrm{M}$ order (isolated vs. connected contrasts: $\mathrm{t} 332=-4.72, P<0.001$ and $\mathrm{t} 332=$ $-4.61, P<0.001$ for stage and body mass, respectively). These significant differences in body mass are explained by differences in the developmental rate of tadpoles (no significant population effect after taking developmental stage into account; Table 3).

Tadpoles from interpopulational crosses showed significantly different developmental stages depending on the female populations in both predation treatments (significant female pop. $\times$ male pop. interaction, Fig. 2, Table 4A). Tadpoles from crosses between isolated populations showed significantly higher developmental stages than those from intrapopulational crosses (t363 $=4.24, \quad P<0.001)$. These differences were not observed for tadpoles from crosses between connected populations $(\mathrm{t} 363=1.11, P=0.267)$. The body mass of tadpoles from interpopulational crosses was systematically higher than those from intrapopulational crosses in both isolated and connected populations (Fig. 2, Table 4A). These differences in performances were caused by a higher developmental rate of tadpoles (no significant male effect; Table 4B). 


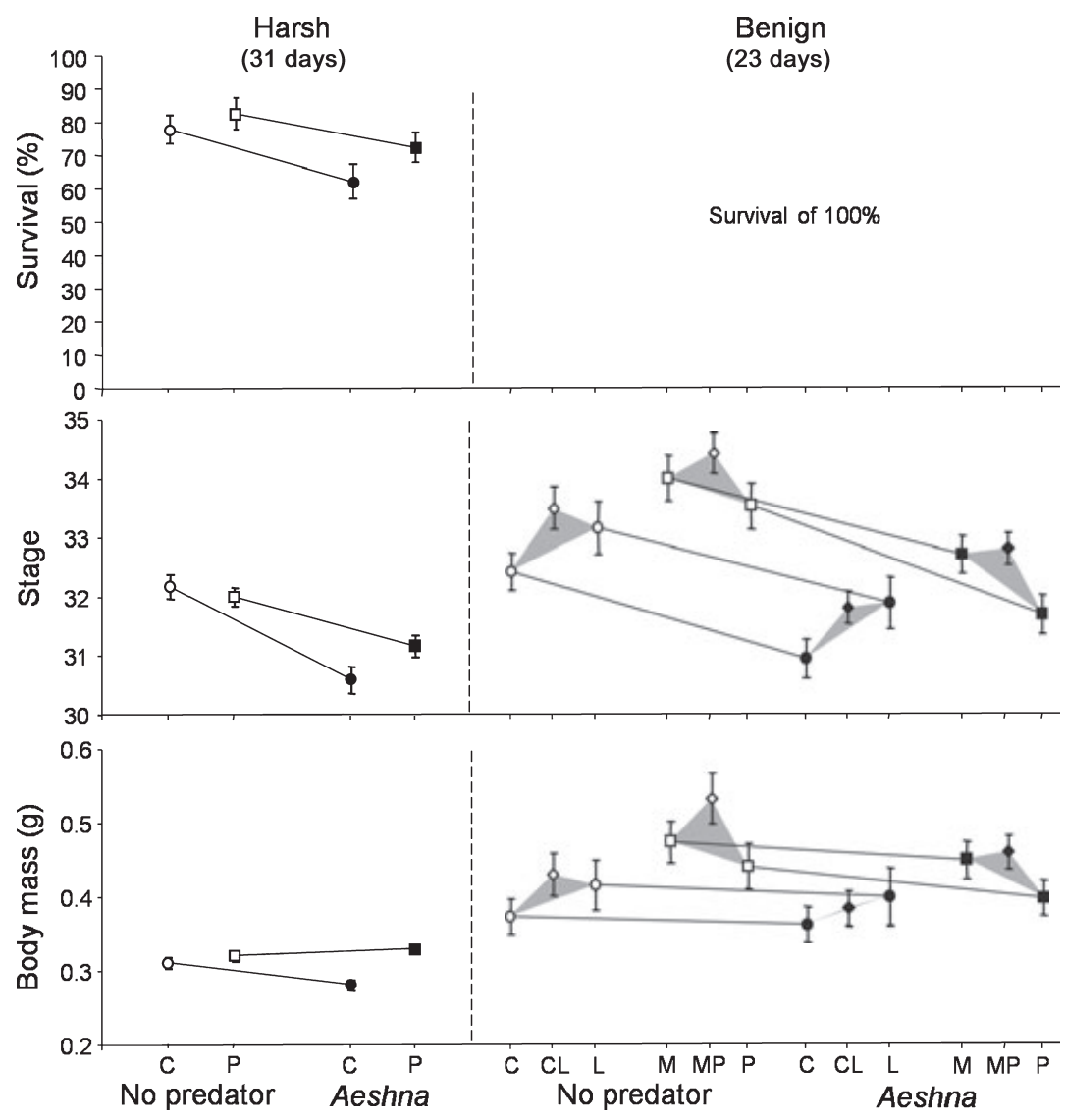

Fig. 2 Survival, developmental stage according to Gosner (1960) and body mass of predator-naïve and predator-induced tadpoles from isolated populations ( $\mathrm{C}$ and $\mathrm{L}$, circle symbol), connected populations ( $\mathrm{M}$ and $\mathrm{P}$, square symbol) in harsh and benign environmental conditions and interpopulational crosses (CL and MP, diamond symbol) in benign conditions. For each interpopulational cross, maternal populations are on the left and paternal on the right. Lines represent the reaction norms. Shaded triangles point upwards in case of heterosis. Values are means \pm SE.

Table 2 Mixed-model analyses of variance for developmental performances of tadpoles from isolated and connected populations (intrapopulational crosses) in (A) benign and (B) harsh conditions. The random effects are shown in italic (excepted for survival analysis, all effects are fixed). The nonsignificant interactions were all excluded from the final models. Estimates and standard errors are presented in appendix (Table S1).

\begin{tabular}{|c|c|c|c|c|c|c|c|c|c|}
\hline \multirow[b]{2}{*}{ Source } & \multicolumn{4}{|c|}{ Stage } & & \multicolumn{4}{|l|}{ Body mass } \\
\hline & \multicolumn{2}{|c|}{ n.d.f., d.d.f. } & $F$ & \multicolumn{2}{|l|}{$P$} & n.d.f., d.d.f. & \multicolumn{2}{|l|}{$F$} & \multirow[t]{2}{*}{$P$} \\
\hline \multicolumn{9}{|l|}{ (A) } & \\
\hline Predation & \multicolumn{2}{|c|}{1,14} & 2.818 & 0.115 & & 1,14 & \multicolumn{2}{|c|}{0.133} & 0.721 \\
\hline Population & \multicolumn{2}{|c|}{ 3, 332} & 15.140 & $<0.001$ & & 3, 332 & \multicolumn{2}{|c|}{11.576} & $<0.001$ \\
\hline \multirow[t]{2}{*}{ Tank [predation] } & \multicolumn{2}{|c|}{14,332} & \multirow[t]{2}{*}{22.873} & $<0.001$ & & 14,332 & \multicolumn{2}{|c|}{37.940} & $<0.001$ \\
\hline & \multicolumn{2}{|c|}{ Survival } & & \multicolumn{3}{|l|}{ Stage } & \multicolumn{3}{|l|}{ Body mass } \\
\hline Source & d.f. & $\chi^{2}$ & $P$ & n.d.f., d.d.f. & $F$ & $P$ & n.d.f., d.d.f. & $F$ & $P$ \\
\hline \multicolumn{10}{|l|}{ (B) } \\
\hline Predation & 1 & 12.320 & $<0.001$ & 1,3 & 6.440 & 0.094 & 1,2 & 0.207 & 0.706 \\
\hline Population & 1 & 4.210 & 0.04 & 1,1 & 0.355 & 0.658 & 1,1 & 2.633 & 0.352 \\
\hline Predation $\times$ population & & & & 1,277 & 3.433 & 0.065 & 1,277 & 6.562 & 0.011 \\
\hline Tank [predation] & 6 & 11.520 & 0.074 & 6,277 & 3.789 & 0.001 & 6,277 & 2.611 & 0.018 \\
\hline
\end{tabular}


Table 3 Mixed-model analyses of covariance for body mass of tadpoles from isolated and connected populations (intrapopulational crosses) in harsh and benign conditions. The random effects are shown in italic. The nonsignificant interactions were all excluded from the final models. Estimates and standard errors are presented in appendix (Table S2).

\begin{tabular}{|c|c|c|c|c|c|c|}
\hline \multirow{2}{*}{$\begin{array}{l}\text { Body mass } \\
\text { Source }\end{array}$} & \multicolumn{3}{|l|}{ Harsh } & \multicolumn{3}{|l|}{ Benign } \\
\hline & n.d.f., d.d.f. & $F$ & $P$ & n.d.f., d.d.f. & $F$ & $P$ \\
\hline Predation & 1,1 & 3.106 & 0.378 & 1,14 & 3.771 & 0.072 \\
\hline Stage $\times$ predation & 1,275 & 11.146 & 0.001 & & & \\
\hline Population & 1,1 & 5.794 & 0.251 & 3, 331 & 0.620 & 0.602 \\
\hline Tank [predation] & 6,275 & 0.357 & 0.905 & 14,331 & 13.241 & $<0.001$ \\
\hline
\end{tabular}

Table 4 Mixed-model analyses of (A) variance and (B) covariance for developmental performances of tadpoles from intra- and interpopulational crosses in benign conditions. The random effects are shown in italic. The nonsignificant interactions were all excluded from the final models. Estimates and standard errors are presented in appendix (Table S3).

\begin{tabular}{|c|c|c|c|c|c|c|}
\hline \multirow[b]{2}{*}{ Source } & \multicolumn{3}{|l|}{ Stage } & \multicolumn{3}{|l|}{ Body mass } \\
\hline & n.d.f., d.d.f. & $F$ & $P$ & n.d.f., d.d.f. & $F$ & $P$ \\
\hline \multicolumn{7}{|l|}{ (A) } \\
\hline Predation & 1,14 & 3.372 & 0.0876 & 1,14 & 0.204 & 0.658 \\
\hline Male population & 1,1 & 2.908 & 0.338 & 1,364 & 8.349 & 0.004 \\
\hline Female population & 1,1 & 13.271 & 0.171 & 1,364 & 63.262 & $<0.001$ \\
\hline Female population $\times$ male population & 1,363 & 4.934 & 0.027 & & & \\
\hline \multirow[t]{2}{*}{ Tank [predation] } & 14,363 & 25.238 & $<0.001$ & 14,364 & 44.775 & $<0.001$ \\
\hline & \multicolumn{3}{|c|}{ Body mass } & & & \\
\hline Source & \multicolumn{2}{|c|}{ n.d.f., d.d.f. } & \multicolumn{2}{|r|}{ F } & & $P$ \\
\hline \multicolumn{7}{|l|}{ (B) } \\
\hline Stage & \multicolumn{2}{|c|}{1,363} & \multicolumn{2}{|r|}{488.405} & & $<0.001$ \\
\hline Male population & \multicolumn{2}{|c|}{ 1, 363} & \multicolumn{2}{|r|}{0.004} & & 0.9466 \\
\hline Female population & \multicolumn{2}{|c|}{1,363} & \multicolumn{2}{|r|}{6.852} & & 0.009 \\
\hline Tank [predation] & \multicolumn{2}{|c|}{14,363} & \multicolumn{2}{|r|}{14.400} & & $<0.001$ \\
\hline
\end{tabular}

In harsh conditions, tadpoles from isolated populations had a lower survival than those from connected population although developmental and growth performances were similar in the absence of predator (Fig. 2, Table 2B).

\section{Effects of genetic erosion on phenotypic plasticity}

All predator-exposed tadpoles developed relatively deeper tails than predator-naïve tadpoles, whatever the populations and the environmental conditions (nonsignificant population $\times$ predation interaction in all conditions, Fig. 3, Table 5). Similarly, interpopulational crosses did not affect tail fin depth (Table 5).

In benign conditions, all tadpoles survived until the measurements of performances (23 days). Predators seem to cause a slower developmental rate (Fig. 2). However, because the random tank effect was high, the main effect of predation was not or marginally significant for this trait (Tables 2A and 4A). Moreover, in the benign conditions (ad libitum diet particularly), tadpole body mass was not affected by the presence of predators (Fig. 2, Tables 2A and 4A).

In harsh conditions, all predator-exposed tadpoles exhibited in contrast a lower survival and a delayed developmental rate (Fig. 2, Table 2B). However, exposure to predators clearly altered more strongly the development and growth of tadpoles from the isolated population in these conditions (significant predation $\times$ population interaction, Fig. 2, Table 2 B). Predator-exposed tadpoles from the isolated population had a lower developmental stage (marginally significant) and body mass than those from connected population. The same pattern exists for survival but is not significant (Fig. 2, Table 2B). Moreover, despite correction on developmental stage, in the predation treatment, tadpoles from isolated population had a significantly lower body mass than those from connected populations (significant predation $\times$ population interaction, Table 3 ). 


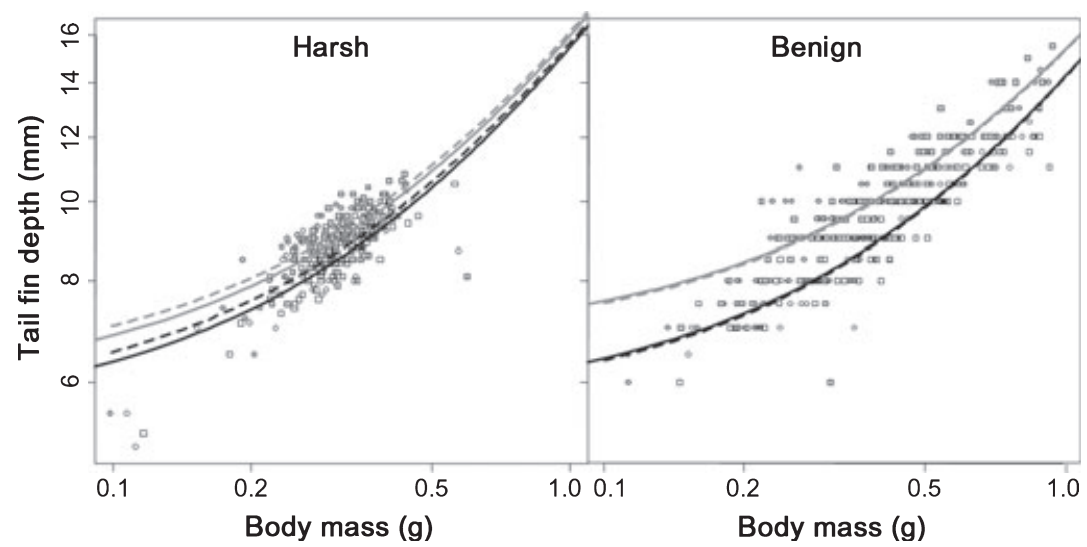

Fig. 3 Tail fin depth responses (corrected on body mass; log-log scale) of predator-induced (grey) and predator-naïve (black) tadpoles from isolated (dashed line) and connected (solid line) populations in harsh and benign conditions. Open and filled symbols show the naïve and the induced tadpoles, respectively. For the sake of clarity, in benign conditions both populations within population status are not distinguished and interpopulational crosses are not represented.

Table 5 Mixed-model analyses of covariance for log (tail fin depth) in harsh and benign conditions. The first analysis (intrapopulational crosses) compared tadpoles from isolated and connected populations. The second analysis compared tadpoles from intra- and interpopulational crosses to determine a heterotic effect. The random effects are shown in italic. The nonsignificant interactions were all excluded from the final models. Estimates and standard errors are presented in appendix (Table S4).

\begin{tabular}{|c|c|c|c|c|c|c|c|}
\hline \multirow[b]{2}{*}{ Log (tail fin depth) } & \multirow[b]{2}{*}{ Source } & \multicolumn{3}{|l|}{ Harsh } & \multicolumn{3}{|l|}{ Benign } \\
\hline & & n.d.f., d.d.f. & $F$ & $P$ & n.d.f., d.d.f. & $F$ & $P$ \\
\hline \multirow{4}{*}{ Intrapop } & Log (body mass) & 1,277 & 639.097 & $<0.001$ & 1,331 & 1124.864 & $<0.001$ \\
\hline & Predation & 1,6 & 53.080 & $<0.001$ & 1,14 & 116.725 & $<0.001$ \\
\hline & Population & 1,277 & 14.419 & $<0.001$ & 3,331 & 0.778 & 0.507 \\
\hline & Tank [predation] & 6,277 & 1.363 & 0.229 & 6,277 & 2.454 & 0.003 \\
\hline \multirow[t]{5}{*}{ Interpop } & Log (body mass) & & & & 1,363 & 586.056 & $<0.001$ \\
\hline & Predation & & & & 1,14 & 146.046 & $<0.001$ \\
\hline & Male population & & & & 1,363 & 0.231 & 0.631 \\
\hline & Female population & & & & 1,363 & 1.881 & 0.171 \\
\hline & Tank [predation] & & & & 14,363 & 1.785 & 0.039 \\
\hline
\end{tabular}

\section{Discussion}

We investigated the impact of genetic erosion on developmental performances and more specifically on phenotypic plastic responses and provide the first evidence that the expression of phenotypic plasticity can be maintained in populations submitted to genetic erosion but at the expense of higher costs (reduced survival, lower developmental and growth rates). We have also confirmed an effect of genetic erosion on fitness in reducing tadpole performances but with variable intensity depending on environmental conditions. These two points will be discussed.

\section{Effect of genetic erosion on mean population fitness}

As we expected, tadpoles from isolated populations performed significantly worse than those from connected populations. Even under benign conditions (normoxia, ad libitum diet) and in the absence of predators, tadpoles from isolated populations exhibited a slower development leading to a reduction in body mass. These modifications have potentially important consequences on individual fitness because these individuals are expected to metamorphose later and/or with higher mortality (Wilbur, 1984). Late metamorphosis may be highly detrimental to future fitness through its impact on adult survival and reproduction success (Altwegg $\delta$ Reyer, 2003).

Two causes could explain this pattern. Delayed development and reduced growth rate could be consequences of small population size and genetic erosion. Theory predicts that genetic erosion in small isolated populations reduces mean fitness through accumulated inbreeding and genetic load, increasing the risk of population extinction (Hedrick, 2001; Frankham et al., 2002; Keller 
\& Waller, 2002; Reed, 2005). Alternatively, differences in the population environments may lead, under a scenario of local adaptation, to quick divergence in some variables related to ecological performances because of microevolutionary events (see Beebee, 2005 for review; Johansson et al., 2007; Richter-Boix et al., 2010). Indeed, although all the ponds are in the same region with homogeneous climatic conditions and are ecologically similar in terms of hydroperiod, vegetation and the presence of predators (Luquet et al., personal observation), we could not totally exclude that populations experience different environmental conditions. Moreover, variation in the availability of resources with worse terrestrial and pond conditions for isolated populations could decrease female physiological condition and ability to invest in their progeny, leading to reduced individual performances in offspring.

Our results on interpopulational crosses support the idea that the low performances of tadpoles from isolated populations are largely a consequence of genetic load and not of maternal effects. In the two isolated populations, the maternal population was not the best parental population (lower performances in intrapopulational crosses than the paternal populations). Consequently, maternal effects would tend to generate negative, rather than positive heterosis. Yet, offspring from crosses between isolated populations were phenotypically superior not only to the midparent values, but also to the best parental population (the paternal population, L). This provides evidence that heterosis is manifest in these interpopulational crosses and that inbreeding exists in our isolated populations, contributing to reduce performances for some larval traits. These results are consistent with a majority of studies that detect a positive relationship between genetic diversity and mean fitness across populations (e.g. Reed \& Frankham, 2003 and references cited therein; Rowe \& Beebee, 2003).

Although our experimental results suggest that genetic erosion in our isolated populations may lead to a reduced fitness in favourable environmental conditions, surprisingly, developmental and growth performances were similar in isolated and connected populations in harsh conditions ( $\mathrm{C}$ and $\mathrm{P}$ ). However and consistently with our expectations, we found that tadpoles from isolated population (C) had a lower survival in these conditions. Halverson et al. (2006) observed a similar effect of inbreeding on the performances of wood frog (Rana sylvatica) larvae in the field. The authors showed a significant negative relationship between inbreeding and survival in the wild, but there was no evidence that inbreeding influenced growth or development. Exposition to such severe stress (i.e. restricted diet and permanent low oxygen concentration in our case or wild conditions) could lead individuals to mobilize resources to survive and minimize allocation to development and growth, concealing the effects of inbreeding on these two performances (Kalinowski \& Hedrick, 1999). Finally, these contrasted results confirm that environmental stress may increase the effect of inbreeding on fitness (Armbruster \& Reed, 2005), but that such effects, which are not consistently observed, should be not generalized (Keller \& Waller, 2002; Szulkin \& Sheldon, 2007; Willi et al., 2007a; Waller et al., 2008).

\section{Effects of genetic erosion on phenotypic plasticity}

We expected genetic erosion to alter phenotypic plasticity patterns by (i) a reduced expression of inducible defences; (ii) increased phenotypic costs in some fitness-related traits. Our results showed the expression of inducible defences by tadpoles from isolated populations has been maintained to a similar level than in connected populations despite a slower development. Hyla arborea tadpoles from isolated populations increased their tail fin depth in the presence of predator just as tadpoles from large connected populations did, regardless of the environmental conditions in the experiments. Similarly, interpopulational crosses did not change plastic response of tadpoles, whereas they did increase basic performances in isolated populations. Thus, induced defences do not seem to be affected by recessive deleterious mutations as are fitness traits. There are several possible explanations to this result. First, predation may be such a strong selective force acting against the drift effect in isolated populations that anti-predator defences are maintained (Lardner, 2000).

Indeed, in environments where predation risk is variable and unpredictable, inducible defences are crucial for the survival of anuran tadpoles (Van Buskirk et al., 2003; Teplitsky et al., 2005c). Second, the genetic architecture of plasticity may differ from that of basic fitness traits. The main origin of inbreeding load is directional dominance variance caused by detrimental, partially recessive mutations (Charlesworth \& Charlesworth, 1999). These mutations tend to decrease growth, developmental rates and physiological performances (Houle et al., 1996; Houle, 1998), but the number of genes involved in these traits is probably higher than the number of genes involved in inducible defences. Consequently, the probability of having some genes involved in plasticity with deleterious mutation increase with the number of deleterious mutations in the genome and then with the degree of inbreeding. This may be supported by Auld \& Relyea (2010) study that compared inducible defences of a hermaphrodic snails Physa acuta in the presence and absence of chemical cues from predatory crayfish. The highly inbred snails from self-crosses exhibited reduced inducible defences relative to outcrossed lineages. In our isolated populations, inbreeding may be not strong enough to lead to deleterious mutations in genetic architecture of plasticity.

In benign conditions, the expression of inducible defences lead to phenotypic costs for all tadpoles in terms of growth and developmental rates, as consistently 
observed in the literature (McCollum \& Leimberger, 1997; Van Buskirk et al., 1997; Van Buskirk \& Relyea, 1998; Relyea \& Werner, 2000; Teplitsky et al., 2005c). These costs were similar for tadpoles from isolated and connected populations.

Our results obtained in harsh environmental conditions show, however, that when they are physiologically challenged to cope with hypoxic conditions and starvation, tadpoles from an isolated population pay a higher fitness cost for inducible defences than do tadpoles from a connected population. All tadpoles allocated resources in inducible defences, but in tadpoles from the isolated population this allocation was at the expense of survival, growth and developmental rates. We can reasonably expect that these higher costs of the induced phenotypes paid during the larval stage will extend to the metamorphosis and ultimately result in a substantial reduction in total fitness. Although we do not have performances at metamorphosis because of very high mortality (> 80\%) because of harsh conditions, we still observed the same patterns at forelimbs emergence (Gosner stage 42) with a trend for reduced survival and a longer larval period for predator-induced tadpoles from isolated populations (Table S6; Fig. S2). These results support the hypothesis that inbreeding, although it does not compromise inducible defences themselves, decreases the overall energy budget of developing tadpoles in such a way that the allocation of resources towards defence comes at a higher cost. This cost remains unexpressed when food and oxygen are abundant enough, but becomes important when total metabolic fluxes are limited by starvation and low oxygen concentrations.

\section{Conclusions}

Our study confirmed that genetic erosion and inbreeding in small isolated populations have a negative effect on mean fitness in natural amphibian populations. Second, phenotypic plasticity patterns (i.e. inducible defences) are maintained in the face of genetic erosion, even in adverse conditions, while most basic fitness traits decrease; yet, when facing several physiological challenges at the same time (i.e. predator cues and metabolic stress), tadpoles from a small isolated population pay a higher fitness cost for their inducible defences. This may lead to an important additional loss of fitness in small fragmented populations. Consequently, as phenotypic plasticity represents a central component of adaptation for many species, it deserves more empirical attention in the framework of genetic erosion.

\section{Acknowledgments}

This research was funded by the ANR Colapse (grant no. BLAN06-1-158238) and the Conseil Général de l'Isère. We warmly thank Julien Chiaffi, Jessica Cote, Romain Gautron, Jérôme Prunier, Delphine Serol and Céline
Viallet for their precious help and support on the field and laboratory. We also thank Isabelle Drillat from the Office National des Forêts, André Miquet from the Conservatoire du Patrimoine Naturel de Savoie and the staff of Lo Parvi and Avenir for their support in the field. Constructive comments on the manuscript were provided by two anonymous reviewers, and two native English speakers C. Richardson and T. Garner for linguistic corrections. This study was conducted with the approval of Préfecture de l'Isère (decision 2007-03328), in accordance with the current laws in France and under the approval of the Direction of Veterinary Services (DSV permit $n^{\circ} 69266347$ ).

\section{References}

Altwegg, R. \& Reyer, H.U. 2003. Patterns of natural selection on size at metamorphosis in water frogs. Evolution 57: 872-882.

Andersen, L.W., Fog, K. \& Damgaard, C. 2004. Habitat fragmentation causes bottlenecks and inbreeding in the European tree frog (Hyla arborea). Proc. R. Soc. Lond. B Biol. Sci. 271: $1293-$ 1302.

Armbruster, P. \& Reed, D.H. 2005. Inbreeding depression in benign and stressful environments. Heredity 95: 235-242.

Auld, J.R. \& Relyea, R.A. 2010. Inbreeding depression in adaptive plasticity under predation in a freshwater snail. Biol. Lett. 6: 222-224.

Auld, J.R., Agrawal, A.A. \& Relyea, R.A. 2010. Re-evaluating the costs and limits of adaptive phenotypic plasticity. Proc. $R$. Soc. B 277: 503-511.

Beebee, T.J.C. 2005. Conservation genetics of amphibians. Heredity 95: 423-427.

Berg, H., Becker, U. \& Matthies, D. 2005. Phenotypic plasticity in Carlina vulgaris: effects of geographical origin, population size, and population isolation. Oecologia 143: 220-231.

Bijlsma, R., Bundgaard, J. \& Boerema, A.C. 2000. Does inbreeding affect the extinction risk of small populations? Predictions from Drosophila. J. Evol. Biol. 13: 502-514.

Broquet, T., Angelone, S., Jaquiéry, J., Joly, P., Léna, J.-P., Lengagne, T., Plénet, S., Luquet, E. \& Perrin, N. 2010. Disconnection can drive genetic signatures of bottleneck: a case study in European tree frogs. Conserv. Biol., doi: 10.1111/ j.1523-1739.2010.01556.x.

Callahan, H.S., Maughan, H. \& Steiner, U.K. 2008. Phenotypic plasticity, costs of phenotypes, and costs of plasticity toward an integrative view. Year Evol. Biol. 2008 1133: 44-66.

Capellan, E. \& Nicieza, A.G. 2007. Non-equivalence of growth arrest induced by predation risk or food limitation: contextdependent compensatory growth in anuran tadpoles. J. Anim. Ecol. 76: 1026-1035.

Charlesworth, B. \& Charlesworth, D. 1999. The genetic basis of inbreeding depression. Genet. Res. 74: 329-340.

Cushman, S.A. 2006. Effects of habitat loss and fragmentation on amphibians: a review and prospectus. Biol. Cons. 128: 231-240.

DeWitt, T.J., Sih, A. \& Wilson, D.S. 1998. Costs and limits of phenotypic plasticity. Trends Ecol. Evol. 13: 77-81.

Fog, K. 1993. Migration in the tree frog Hyla arborea. In: Ecology and Conservation of the European Tree Frog (H.P. Stumpel $\delta$ U. Tester, eds), pp. 55-64. DLO Institute for Forestry and Nature Research, Wageningen, the Netherlands. 
Frankham, R., Ballou, J.D. \& Briscoe, D.A. 2002. Introduction to Conservation Genetics. Cambridge University Press, Cambridge.

Gallant, A.L., Klaver, R.W., Casper, G.S. \& Lannoo, M.J. 2007. Global rates of habitat loss and implications for amphibian conservation. Copeia 4: 967-979.

Gosner, K.L. 1960. A simplified table for staging anuran embryos and larvae with notes on identification. Herpetologica 16: 183190.

Halverson, M.A., Skelly, D.K. \& Caccone, A. 2006. Inbreeding linked to amphibian survival in the wild but not in the laboratory. J. Hered. 97: 499-507.

Hedrick, P.W. 2001. Conservation genetics: where are we now? Trends Ecol. Evol. 16: 629-636.

Hooftman, D.A.P., van Kleunen, M. \& Diemer, M. 2003. Effects of habitat fragmentation on the fitness of two common wetland species, Carex davalliana and Succisa pratensis. Oecologia 134: 350-359.

Houle, D. 1998. How should we explain variation in the genetic variance of traits? Genetica 102-3: 241-253.

Houle, D., Morikawa, B. \& Lynch, M. 1996. Comparing mutational variabilities. Genetics 143: 1467-1483.

Huber, H., Kane, N.C., Nolan, C., Heschel, M.S., von Wettberg, E.J., Eric, J., Banta, J., Leuck, A.M. \& Schmitt, J. 2004 Frequency and microenvironmental pattern of selection on plastic shade avoidance traits in a natural population of Impatiens capensis. Am. Nat. 163: 548-563.

Johansson, M., Primmer, C.R. \& Merila, J. 2007. Does habitat fragmentation reduce fitness and adaptability? A case study of the common frog (Rana temporaria). Mol. Ecol. 16: 26932700.

Kalinowski, S.T. \& Hedrick, P.W. 1999. Detecting inbreeding depression is difficult in captive endangered species. Anim. Conserv. 2: 131-136.

Keller, L.F. \& Waller, D.M. 2002. Inbreeding effects in wild populations. Trends Ecol. Evol. 17: 230-241.

Lardner, B. 2000. Morphological and life history responses to predators in larvae of seven anurans. Oikos 88: 169-180.

Laurila, A., Karttunen, S. \& Merila, J. 2002. Adaptive phenotypic plasticity and genetics of larval life histories in two Rana temporaria populations. Evolution 56: 617-627.

Lesbarreres, D., Pagano, A. \& Lode, T. 2003. Inbreeding and road effect zone in a Ranidae: the case of Agile frog, Rana dalmatina Bonaparte, 1840. C. R. Biol. 326: S68-S72.

McCollum, S.A. \& Leimberger, J.D. 1997. Predator-induced morphological changes in an amphibian: predation by dragonflies affects tadpole shape and color. Oecologia 109: 615-621.

Merila, J., Laurila, A. \& Lindgren, B. 2004. Variation in the degree and costs of adaptive phenotypic plasticity among Rana temporaria populations. J. Evol. Biol. 17: 1132-1140.

Paschke, M., Bernasconi, G. \& Schmid, B. 2003. Population size and identity influence the reaction norm of the rare, endemic plant Cochlearia bavarica across a gradient of environmental stress. Evolution 57: 496-508.

Pertoldi, C., Bijlsma, R. \& Loeschcke, V. 2007. Conservation genetics in a globally changing environment: present problems, paradoxes and future challenges. Biodivers. Conserv. 16: 4147-4163.

Pigliucci, M. 2005. Evolution of phenotypic plasticity: where are we going now? Trends Ecol. Evol. 20: 481-486.

Pinheiro, J.C. \& Bates, D.M. 2000. Mixed-Effects Models in $S$ and $S$-PLUS. Springer, New York.
Pluess, A.R. \& Stocklin, J. 2004. Genetic diversity and fitness in Scabiosa columbaria in the Swiss Jura in relation to population size. Conserv. Genet. 5: 145-156.

Reed, D.H. 2005. Relationship between population size and fitness. Conserv. Biol. 19: 563-568.

Reed, D.H. \& Bryant, E.H. 2004. Phenotypic correlations among fitness and its components in a population of the housefly. J. Evol. Biol. 17: 919-923.

Reed, D.H. \& Frankham, R. 2003. Correlation between fitness and genetic diversity. Conserv. Biol. 17: 230-237.

Relyea, R.A. 2004. Fine-tuned phenotypes: tadpole plasticity under 16 combinations of predators and competitors. Ecology 85: $172-179$.

Relyea, R.A. \& Werner, E.E. 2000. Morphological plasticity in four larval anurans distributed along an environmental gradient. Copeia 1: 178-190.

Richter-Boix, A., Teplitsky, C., Rogell, B. \& Laurila, A. 2010. Local selection modifies phenotypic divergence among Rana temporaria populations in the presence of gene flow. Mol. Ecol. 19: $716-731$.

Rowe, G. \& Beebee, T.J.C. 2003. Population on the verge of a mutational meltdown? Fitness costs of genetic load for an amphibian in the wild. Evolution 57: 177-181.

Schlichting, C.D. 2008. Hidden reaction norms, cryptic genetic variation, and evolvability. Year Evol. Biol. 2008 1133: 187-203.

Sultan, S.E. 2000. Phenotypic plasticity for plant development, function and life history. Trends Plant Sci. 5: 537-542.

Szulkin, M. \& Sheldon, B.C. 2007. The environmental dependence of inbreeding depression in a wild bird population. PLOS ONE 2: e1027.

Teplitsky, C. \& Laurila, A. 2007. Flexible defense strategies: competition modifies investment in behavioral vs. morphological defenses. Ecology 88: 1641-1646.

Teplitsky, C., Plenet, S. \& Joly, P. 2003. Tadpoles' responses to risk of fish introduction. Oecologia 134: 270-277.

Teplitsky, C., Plenet, S. \& Joly, P. 2004. Hierarchical responses of tadpoles to multiple predators. Ecology 85: 2888-2894.

Teplitsky, C., Piha, H., Laurila, A. \& Merila, J. 2005a. Common pesticide increases costs of antipredator defenses in Rana temporaria tadpoles. Environ. Sci. Technol. 39: 6079-6085.

Teplitsky, C., Plenet, S. \& Joly, P. 2005b. Costs and limits of dosage response to predation risk: to what extent can tadpoles invest in anti-predator morphology? Oecologia 145: 364-370.

Teplitsky, C., Plenet, S., Lena, J.P., Mermet, N., Malet, E. \& Joly, P. 2005c. Escape behaviour and ultimate causes of specific induced defences in an anuran tadpole. J. Evol. Biol. 18: 180-190.

Van Buskirk, J. 2000. The costs of an inducible defense in anuran larvae. Ecology 81: 2813-2821.

Van Buskirk, J. 2002. A comparative test of the adaptive plasticity hypothesis: relationships between habitat and phenotype in anuran larvae. Am. Nat. 160: 87-102.

Van Buskirk, J. \& Arioli, M. 2002. Dosage response of an induced defense: how sensitive are tadpoles to predation risk? Ecology 83: 1580-1585.

Van Buskirk, J. \& McCollum, S.A. 2000. Functional mechanisms of an inducible defence in tadpoles: morphology and behaviour influence mortality risk from predation. J. Evol. Biol. 13: 336-347.

Van Buskirk, J. \& Relyea, R.A. 1998. Selection for phenotypic plasticity in Rana sylvatica tadpoles. Biol. J. Linn. Soc. 65: 301-328. 
Van Buskirk, J. \& Steiner, U.K. 2009. The fitness costs of developmental canalization and plasticity. J. Evol. Biol. 22: 852-860.

Van Buskirk, J., McCollum, S.A. \& Werner, E.E. 1997. Natural selection for environmentally induced phenotypes in tadpoles. Evolution 51: 1983-1992.

Van Buskirk, J., Muller, C., Portmann, A. \& Surbeck, M. 2002. A test of the risk allocation hypothesis: tadpole responses to temporal change in predation risk. Behav. Ecol. 13: 526530.

Van Buskirk, J., Anderwald, P., Lupold, S., Reinhardt, L. \& Schuler, H. 2003. The lure effect, tadpole tail shape, and the target of dragonfly strikes. J. Herpetol. 37: 420-424.

Waller, D.M., Dole, J. \& Bersch, A.J. 2008. Effects of stress and phenotypic variation on inbreeding depression in Brassica rapa. Evolution 62: 917-931.

Wilbur, H.M. 1984. Complex life cycles and community organization in amphibians. In: A New Ecology: Novel Approaches to Interactive Systems (P.W. Price, C.N. Slobodchikoff \& W.S. Gaud, eds), pp. 195-224. John Wiley and Sons, New York, USA.

Willi, Y., Van Buskirk, J. \& Hoffmann, A.A. 2006. Limits to the adaptive potential of small populations. Annu. Rev. Ecol. Evol. Syst. 37: 433-458.

Willi, Y., Dietrich, S., van Kleunen, M. \& Fischer, M. 2007a. Inter-specific competitive stress does not affect the magnitude of inbreeding depression. Evol. Ecol. Res. 9: 959-974.

Willi, Y., Van Buskirk, J., Schmid, B. \& Fischer, M. 2007b. Genetic isolation of fragmented populations is exacerbated by drift and selection. J. Evol. Biol. 20: 534-542.

\section{Supporting information}

Additional Supporting Information may be found in the online version of this article:

Figure S1 Tail and body morphological responses (corrected on body mass; log-log scale) of predator-induced (grey) and predator-naïve (black) tadpoles from isolated (dashed line) and connected (solid line) populations in harsh conditions.
Figure S2 Survival and larval period at Gosner stage 42 (emergence of forelimbs) of predator-naïve and predatorinduced from the $\mathrm{C}$ isolated population (circle symbol) and $\mathrm{P}$ connected population (square symbol) in harsh environmental conditions.

Table S1 Estimates and standard errors of mixed-model analyses of variance for developmental performances of tadpoles from isolated and connected populations (intrapopulational crosses) in (A) benign and (B) harsh conditions (Table 2).

Table S2 Estimates and standard errors of mixed-model analyses of covariance for body mass of tadpoles from isolated and connected populations (intrapopulational crosses) in harsh and benign conditions (Table 3 ).

Table S3 Estimates and standard errors of mixed-model analyses of (A) variance and (B) covariance for developmental performances of tadpoles from intra- and interpopulational crosses in benign conditions (Table 4).

Table S4 Estimates and standard errors of mixed-model analyses of covariance for log (tail fin depth) in harsh and benign conditions (Table 5).

Table S5 Mixed-model analyses of covariance for log (tail length), log (tail muscle depth), log (body length) and log (body depth) in harsh conditions.

Table S6 Mixed-model analyses of variance for performances of froglets from isolated and connected populations at Gosner stage 42 in harsh conditions.

As a service to our authors and readers, this journal provides supporting information supplied by the authors. Such materials are peer-reviewed and may be reorganized for online delivery, but are not copy-edited or typeset. Technical support issues arising from supporting information (other than missing files) should be addressed to the authors.

Received 2 June 2010; revised 13 September 2010; accepted 14 September 2010 